\title{
Combating World Pandemics through Complementarity of Indigenous Knowledge with other Knowledge Systems: A Paradigm Shift in Healthcare Research and Education
}

\author{
Hassan O. Kaya \\ ORCID iD: https://orcid.id/0000-0002-9125-1520
}

Mayashree Chinsamy

ORCID iD: https://orcid.id/0000-0002-9138-8762

\begin{abstract}
Using a telecommunication survey and a purposive sample of 32 African indigenous knowledge holders (IK Holders) and practitioners, from across cultures, the Centre in Indigenous Knowledge Systems (CIKS) at the University of KwaZulu-Natal, South Africa, investigated their views on COVID-19 pandemic and the role of IKS in combating the pandemic. They expressed the following sentiments: although the majority of marginalized Africans depend on their community-based knowledge systems for healthcare including against pandemics, these knowledge systems tend to be neglected in the search for sustainable solutions; the IK holders live in local communities with the people, understand their concerns, and assist them with preventive and treatment measures, which are local, holistic, accessible, affordable and culturally acceptable; they conceptualized IK as holistic, cultural, placedbased, spiritual, predominantly oral, multi-generational and inclusive; health and illness are not only physiological and medicinal, but physiological, emotional, psychological and spiritual phenomena;healthcare research in Africa, like formal education, is a tool of colonization and exploitation,
\end{abstract}


befitting outsiders; COVID-19 has revealed the significance of Ubuntu values of care and solidarity, including role of the state. In a matter of weeks, a virus, managed to challenge western liberal democracy, especially its emphasis on the private sector, individualism and minimal role of the state in healthcare. The following recommendations were made: recognition of IK as an integral part of democracy and complementarity of knowledge systems in mitigating global pandemics; since global pandemics have cultural imperatives, sustainable mitigation should not be the left to western science alone; governments should endeavour to mobilize community-based support systems through partnerships with IK holders and traditional leadership, to make interventions inclusive and locally acceptable; indigenous research and education in Africa, require new epistemologies and research methodologies as part of community self-determination; in times of pandemics, communities should be engaged in their own local languages and cultural values to build trust and acceptance of interventions.

Keywords: Indigenous Knowledge Holders, Pandemics, Indigenous Research, Co-Knowledge Production, Complementarity of Knowledge Systems

\section{Introduction}

The outbreak of the coronavirus (COVID-19) has created a serious health danger to marginalized communities globally. These poor communities already experience limited access to healthcare and other basic services, including water, sanitation, transport, food, education and other key preventive measures (Bond 2020). The World Health Organization (WHO) (2020) indicates that even when the poor are able to access these healthcare services, they encounter the problem of communication as the services are not provided in the context of their cultural values and local languages. The paper expresses further the concern that, most policy makers and healthcare service providers do not take into account the cultural lifestyles of local communities as not only a source of their resiliency, but could also be a threat during times of pandemics in preventing the spread of viruses. For instance, most African cultural communities regularly organize large traditional gatherings for special events such as harvests, coming of age ceremonies, 
funerals, weddings etc. They live in multi-generational dwellings, which puts them and their families, at risk. As the number of COVID-19 infections rises globally, as well as the high mortality rates among certain vulnerable groups with underlying health conditions, reliable data on the rate of infection and death, in most local communities, is not available. The information available on infection and preventive measures is not offered in local languages (World Economic Forum 2020). Yet, local communities including the marginalized social groups, do not have the opportunity to express their own concerns, understanding and responses to the pandemic.

The Centre in Indigenous Knowledge Systems (CIKS) at the University of KwaZulu-Natal, South Africa, works closely with IK holders and practitioners, across cultures, within and outside South Africa. The objective of the partnership is to advance a new paradigm shift in coknowledge production, management and protection, for sustain-able development including public healthcare, social and epistemic justice. The CIKS provides IK holders with platforms, using their own indigenous languages, to co-create and share knowledge with different stakeholders, across cultures. Therefore, using a telecommunication survey, supported by exami-nation of secondary data sources, and a purposive sample of $32 \mathrm{IK}$ holders, the CIKS tried to establish their views regarding the role of IK, including research in mitigating pandemics such as COVID-19 (Greenwood 1998). The study was first interested in establishing from the IK holders and practitioners including Traditional healers, the role of African indigenous knowledge systems (AIKS) in combating the COVID-19 pandemic in Africa.

\section{Marginalization of African Indigenous Knowledge Systems during COVID-19 Pandemic}

One prominent academic and traditional healer in South Africa, Prof. Bhedlindaba Mkhize (2020), raised an important concern that, although the outbreak of the COVID-19 pandemic poses a serious concern on the lives of the majority of the marginalized people in South Africa, especially Africans, due to limited access to healthcare, they depend on their indigenous knowledge systems (IKS) including IK holders for basic services. Yet, these knowledge systems and their holders, tend to be marginalized in the search for sustainable solutions to mitigate healthcare challenges, including 
pandemics. He correctly indicated that the recognition of IKS by African governments, in the mitigation of pandemics, both in practice and attitude, would be an important affirmation of the African identity. The mitigation of global pandemics such as COVID-19, with cultural imperatives, should not be left to western science including medicine alone. Prof. Mkhize commended the Ghanaian government for working closely with that country's traditional healers against COVID-19. This should be exemplary to the rest of the continent as the majority of Africans depend on IKS for primary healthcare. This sentiment was expressed by Mme Tumisang Molaakgosi, a traditional healer in Mahikeng, North-West Province, South Africa, who said:

We live in the community with the people, we understand their concerns, traditions and languages. Our role in educating and supporting the broader community in dealing with deadly pandemics such COVID-19 is crucial. The government and health officials must understand this in mobilizing community-based knowledge systems into the public awareness and intervention value chain, to make interventions more acceptable and sustainable. .....

Another IK holder, uBaba Bhekisisa Ngcobo from Nquthu, UMzinyathi District Municipality, KwaZulu-Natal Province, South Africa, said:

The majority of African people, especially in the rural areas, have limited or no access to official public healthcare services. They survive on what is available in their local communities including their traditional medicines. In the case of COVID-19, the government would have checked with local authorities and community knowledge holders, on what is locally available in terms of local knowledge and resources...Traditional healers, if well supported could mobilize and teach young people certain traditional healthcare practices and spiritually help community members remove their fears on the pandemic....

The majority of the IK holders had the view that COVID- 19 pandemic is not the first one in the history of Africa. African IK holders over the years assisted people in their local communities against pandemics through IKS- 
based prevention and treatment measures, which are locally accessible, affordable and culturally acceptable. On the preventive side they knew the right plants and other natural ingredients as food and medicine to boost people's immune systems, provide physical, spiritual, psychological and moral support to individuals and families, including mitigating their fears in stressful times. The government should mobilize these community-based support systems and resources, through partnerships with IK holders and traditional leadership. In the case of those who are already sick with COVID19, the government and official healthcare providers could have been assisted by traditional healers, leadership and family members through providing information if the sick had other underlying conditions which need treatment using complementarity of both traditional and conventional medicines.

For instance, on this issue, one Traditional Healer, Vho Tshifhiwa Mulalo, in Thulamela, Vhembe District, Limpopo Province, South Africa, had the following to say on socio-economic inequality in South Africa:

It's not the first time our people have been impacted by dreadful diseases such COVID-19, from abroad. However, our ancestors ensured that their children, grandchildren and great-grandchildren always have places to access clean water, clean air, our traditional medicine and food systems including places we can quarantine the sick ....

The majority of the IK holders had the view that the outbreak of COVID-19 has exposed the social injustices and inequalities in African societies. The socioeconomic damage that is expected in the wake of the pandemic is a big indicator that, unless AIKS and associated resources are given their due recognition, the consequences might be dire. One IK holder, Mme Bakang Rebaone, in Mamelodi Township, Gauteng Province said:

It is no secret that there are blatant differences between the health of majority of Africans and non-Africans, who mostly live in affluent areas .... Africans fare more poorly than the average non-Africans on virtually all measurable health and life indicators ....

She radically went further to say: 
I would like the government to publish annual progress reports on its attempts to measure and address this unacceptable socioeconomic gap in the country...... There should be more cultural competency training for health and medical professionals, as well as greater efforts to attract and retain African students into the healthcare professions. These suggestions are measurable, achievable and commendable. Nevertheless, one might say, if addressing issues within the official health-care system won't solve the health crises facing the marginalized African communities, then what will? .... Our Indigenous knowledge, which we depend on for centuries....

It is on the basis of the above statement that the CIKS study was interested in establishing the IK holders' understanding of IK. This aspect is presented and discussed in the following section.

\section{African Indigenous Knowledge Holders' Conceptualization of Indigenous Knowledge}

Indigenous knowledge has been given diversity of definitions from a western perspective. The CIKS study wanted to find out the respondent IK holders' conceptualizations of IK. The renowned IK scholar and educator, from Mi'kmaq territory, in Canada, Battiste (2005), outlines the limitations of Eurocentric conceptualizations of IK which tends to: reduce IK to taxonomic categories that are static over time; reduce it to its quantifiably observable empirical elements; and assume that IK has no validity except in the spiritual realm. These approaches, do not adequately explain the cultural, holistic and responsible nature of IK or its fundamental importance to indigenous communities (Kirmayer et al. 2000).

Ortiz (1999) provides an example of the cultural, holistic and inclusive nature of indigenous knowledge production and sharing, especially in healing practices. Example is given on the use of cultural-based structures such as the talking circle, outdoor physical settings, storytelling, and ceremony in knowledge creation and sharing. Getty (2010) explains that this is similar to research focus groups but in this context involving a process whereby each participant in the circle shares ideas with the others without interruption, the talking circle is usually facilitated by an elderly knowledge 
holder, each with her/his own style for conducting a talking circle. Although talking circles may not be perceived as interactive, the presence of a circle, where all members are equal, facing each other, actively listening and sharing their thoughts, elicits interactions that promote engagement of all members in the circle as they co-create knowledge. In these indigenous methods of data collection, the social construction of knowledge and sharing is based on the lived realities of the participants, whereby knowledge is generated and shared in an inclusive and collaborative process. This cultural and placed-based nature of IK was emphasized by all respondent knowledge holders. Wilson (2008) elaborates this aspect by emphasizing that IK is knowledge about people's interaction, understanding and experience of their natural and spiritual environment.

However, the question is whether IK is so culturally dependent such that a person from outside the culture cannot hold it? Abele (1997) explains that it depends on how the knowledge is being produced and shared by local community. An example was given by IK holder, Mme Kerapetse Letang, in Moruleng village, North-West Province, about a person from outside the village who might be inquisitive about the spread of certain indigenous plants in the village. The community members could respond in two ways: Firstly, based on their own observational experience that there a local fruit in the area which are spread through Vervet monkey droppings. This could be the reason why they do not chase the Vervet monkeys because they help them spread the fruits they eat.

Secondly, they might give the outsider an answer that is more culturally complicated for him/her to understand. For instance, in-depth interview with a community knowledge holder, Re Thapelo Mothibi of the Bakgatlaba-ga-Kgafela in Moruleng village, explained culturally, that the Vervet monkey is the totem of the Batswana clan of Bakgatla-ba-ga-Kgafela. This explained why the people are also known as Ba Bina Kgabo or the Vervet monkey. If they say that the Vervet monkey came and talked to our people, the statement on its own for an outsider is next to impossible to deconstruct. Hence, the story of the Vervet monkey having talked to the people, will be clear if the people explain that many generations ago the Vervet monkey showed them its knowledge by telling them that, every day out there: 'I' $m$ your gardener for those fruits you love. I go around and fertilize them, I plant them'. The monkey fertilizes the soil with droppings that allow the fruit seeds to grow in the soil which is very difficult to grow anything. The monkey gave 
the people a gift to help and sustain them because the monkey also likes those fruits. The Vervet monkey is never chased away in the Ba Bina Kgabo communities and never killed because they come to visit the people in their homes.

Agrawal (2005) explains this holistic and relational nature of IK by indicating that IK is place-based and attained through extensive observation of a natural environment, especially land. The latter is not merely the ground, but includes living and non-living things, which are intimately interdependent. The outsider must be open to understand the environment from the perspective of the community. However, Hatcher et al. (2009) indicate that in most knowledge systems, there are some assumptions that can be teased apart from other aspects of the system. For example, certain principles of IK, such as respect for nature, transcend location, and are common across all indigenous cultures.

The IK holders also understood IK as being multi-generational because it is usually shared within and across generations, as cumulative knowledge built over centuries. This distinguishes IK from relatively recent knowledge held by people and it is on the basis of this consideration that the respondent IK holders conceptualized IK as rational and reliable, produced through generations of close contact with the natural environment. They argued that this aspect need not be qualified by western science as it creates the impression that IK is only rational if western science says it is. It places western science in a position of power over IK as it is the case during COVID-19 pandemic. According to them, if IK was not accurate, societies that depended on it over centuries would not have survived the pandemics. Furthermore, IK is changing and dynamic as it has been responsive to environmental, technological, and social changes over centuries, by building upon the experience of earlier generations. It has incorporated external influences, including other knowledge and technology systems (Mazrui 1986).

Brascoupé (2001) explains the limitations of the concept traditional knowledge (TK), when used interchangeably with IK. The word 'traditional' roots IK as the knowledge of the past, whereas IK is changing over time. The respondent IK holders had the view that although IK is predominantly oral in nature, this is problematic due to the marginalisation of indigenous languages in the formal education system. Moreover, since western science is recorded in journals, written communication tends to be privileged. This 
puts IK at a disadvantage, in terms of getting acceptance and recognition in the western scientific community. It is, therefore, important to recognize the importance of the medium in which IK is passed on, given the importance of oral communication in indigenous cultures, and the distinction between oral and non-oral communication in comparing knowledge systems (Olusola 2007).

IK holder emphasized the importance of spirituality in IK as it differentiates it from western science in understanding the world, holistically. For example, Mme Mosetsanagape Tshephang a Traditional Healer from the Barolong Boo Ratlou clan of the Batswana, in Ratlou, NorthWest Province, South Africa had the following remarks on holism of IK:

Making simplifications and generalizations of complex phenomena is 'childish' and without sense....in our Batswana tradition and culture, one of the main features of knowledge, based on centuries of living sustainably with Creation, is its interdependence: the recognition that all aspects of Creation are interrelated.

She gave the example of water by saying:

Water is not a single, discrete aspect of our environment; it is part of a greater, interconnected whole. When one considers water, therefore, one must consider all that to which water is connected and related ....

She understood holism in IK as the complex interconnected nature of the world, especially between humans, natural and the spiritual environment (Fleming et al. 2008). The following sections look at the challenges and prospects of co-knowledge creation and sharing in healthcare research, from the perspective of IK holders and practitioners, especially during pandemics such as the Coronavirus pandemic.

\section{Challenges and Prospects of Co-Knowledge Creation and Sharing in Healthcare Research: An African Indigenous Knowledge Perspective}

Most of the IK holders interviewed raised the concern that western research 
has tended to portray indigenous ways of knowing and value systems as a problem. This assertion is supported by Hart (2010) who indicates that problematizing the 'indigenous' has been an obsession of Western research. The IK holders argued that research in Africa, like western education has been used as a tool of colonization and exploitation. For instance, a Pedi IK holder, Mme Karabo Motshumi in Mogalakwena, Limpopo Province, South Africa said:

The way current research is done in our communities is another form of colonialism and stealing ... We are tired of academic research because it not only treats Africans as objects, but also takes our knowledge away, giving little or nothing back to our communities. We are used as sources of information for people and things we do not know....

This implies that from an indigenous perspective, current research may be termed 'stealing', because it has been used to benefit outsiders and not local communities. This explains the quest for decolonization of research, as one of the contemporary issues in indigenous knowledge research and education, especially among the growing younger generation of IKS researchers. They demand new epistemologies and methodologies in research and education in Africa, which are culturally acceptable and relevant to local communities (Oelofsen 2015). This concern was also articulated by, Oratile Boipelo an IKS postgraduate student at the University of Venda, in South Africa:

The decolonization of research and teaching methods in Africa, and South Africa in particular, is about centering our African indigenous concepts, worldviews, ways of knowing and knowledge production in our own African indigenous perspectives ...Our devotions should be to the marginalized African indigenous people, especially their ways of knowing....

The objective is to build and promote an indigenous body of conceptual approaches and research methods, for studying African indigenous communities and conditions. In line with this concern, Israel et al. (2005) note that academic and political careers, economic and professional gains, profitable use of indigenous natural resources including IKS have benefited 
non- indigenous world using research on indigenous communities and issues. This approach to research has disempowered indigenous communities for centuries.

In their discussion on research and power relations, Denzin et al. (2008) elaborate that research is inseparably related to power and control. Hence the African younger generations of indigenous scholars, are currently taking the issues of power and control in research and education, seriously, as part of self-determination process. In the context of the IK holders themselves, it means being able to make decisions about the research agenda, methodologies and outcomes themselves or inclusively. The CIKS has initiated research and knowledge exchange platforms for IK holders and other stakeholders, across cultures, and in different IK fields, to articulate and reclaim control over indigenous ways of knowing and research, which recognize the significance of complementarity and democracy of knowledge systems, and against the hierarchy of knowledge systems in the global knowledge economy. Olwethu Dlamini, an IKS postgraduate student at University of South Africa (UNISA) argued:

The current processes of theorizing and measuring what is considered to be 'scientifically acceptable' are rooted in Western philosophy, emphasizing the idea of objectivity. This has been questioned by indigenous researchers, as it requires the researcher to remain outside the research experience....... As indigenous scholars we should not look to Western research for solutions to our problems. We need to put our own mark on research, with its outcomes integrated in indigenous education at all levels to make education relevant to African conditions and needs ....

Olusola (2007) supports the above assertions by indicating that African indigenous ways of putting the 'indigenous mark' on research and education, already exist in African home-grown philosophies such as Ubuntu, Batho Pele, Ujamaa, Umuganda, etc. They contain rich conceptual and methodological frameworks which put emphasis on human agency, solidarity, care, respect and responsibility to African people. An important element in these philosophies in the context of indigenous research and knowledge sharing, is the focus on the group rather on the self. It articulates a reciprocal relationship between researchers and researched as 'a family in 
the research process'. These indigenous philosophies also incorporate theoretical values, which tend to be marginalized by western science. Theorizing has been considered a prerogative of western ways of knowing only (Etowa et al. 2007; Battiste 2005). This implies that any research involving indigenous communities should pose and answer the following questions: Whose research is this? Who owns it? Whose interests does it serve? Who will benefit from it? Who has designed its questions and framed its scope? Who will carry it out? Who will write it up? How will the results be disseminated? (Grasswick 2010).

In their discussion of Indigenous Health Research in the context of conceptual and methodological perspectives, Iwama et al. (2009) articulate the concept of two-eyed seeing, as an example of how IK can influence the conduct of western research. Consistent with Ubuntu values of care, respect and solidarity, it explains how community-based participatory research and the principles of ownership, control and access, can help in shaping healthcare research to address priorities of indigenous communities. Agrawal (2005) explains that when two-eyed seeing is integrated into indigenous research on healthcare, it promotes complementarity of ways of knowing by enabling researchers and participants to acknowledge different worldviews. Building on the two-eyed seeing concept, Barth, (2002) brings the concept of ethical space in co- knowledge production and sharing in healthcare research. It means that people with different worldviews move from talking about or to one another to talking together. Whereas two-eyed seeing entails learning to see with the strength of both indigenous and western ways of knowing for the benefit of all, ethical space requires creating space for dialogue between people holding different worldviews (Weber 2001).

The significance of indigenous languages in research and communication, was emphasized by all IK holders in building trust and acceptance of interventions against pandemics. The following section discusses this issue.

\section{African Indigenous Languages in Public Healthcare Communication during Pandemics}

A Tswana traditional healer, Mme Tebogo of Modimola, from Modimola village, near Mahikeng in North-West Province, South Africa had the following to say on indigenous languages and healthcare communication: 
One key barrier for African patients to access western health care is a distrust of healthcare providers. Part of the power of our indigenous healing practices comes from our indigenous languages, especially our songs, stories, ceremonies, that heal a lot of our people. Through them we share the benefits of our healing practices with our patients. Western healthcare providers do not understand and appreciate these values.

This means that the role of indigenous languages in healthcare interventions needs to be acknowledged, if the messages and interventions are to be locally and culturally acceptable as part of holistic approach to healthcare (WHO 2020). In times of a crisis such as COVID-19, when information changes rapidly, having trusted decision makers and communicators in place is very important in communicating confusing messages and interventions. Ma Nomathemba Gumede, an elder from Matimatolo community, UMzinyathi District, KwaZulu-Natal Province, complained on the following:

Accurate information about the Coronavirus such as on hygiene, physical distance, quarantine and prevention must reach everyone, including poor people who do not speak English......... this pandemic is accompanied by a spread of disinformation and misinformation, making it difficult to find accurate lifesaving information ....

The paper reiterates that the appropriate language of communication is crucial during pandemics such as COVID-19, as an intrinsic part of the human rights and fundamental freedom of the healthcare users. The following section discusses the African Ubuntu philosophy in the context of the role of the state in global pandemics such as COVID-19.

\section{African Ubuntu Values and the State During Global Pandemics}

The outbreak of the coronavirus pandemic (Covid-19) offers the world an opportunity to recapture the African spirit of Ubuntu. It emphasizes the human values and social practices of empathy, responsibility and solidarity. Ubuntu is the philosophy of 'I am because we are'. The spread of 
coronavirus serves as a vivid example of how we are all affected by the actions of one another. Contrary to government imposed and western individualistic self-protective approaches that are competitive and aimed at individual isolation, the Ubuntu values implore individuals, communities and families to work together for the purpose of combating a global pandemic.

Ubuntu values and principles demonstrate resilience responses developed and used by social groups in marginalized communities, facing similar life challenges such as COVID-19. It takes into account, resources and social practices available and appropriate, to collectively mitigate against a common problem. In most African conditions characterised by poverty and inequality, examples of collective resilience responses include socioeconomic support where people belong to a collective (stokvel) to share joint finances, lending of goods and services to support severely stretched household incomes, assisting those with limited literacy to complete social grant documents, health support such as home-based care visits to oversee care and treatment, offering transport to take friends and relatives to clinics; education support involves teachers providing children with uniforms or stationery from a school pool (or their pockets), and unemployed youth assisting siblings or others with homework; emotional support includes neighbours assisting with chores and homework, when caregivers may be too ill to do this themselves, or gathering for spiritual support to sing and pray. However, one of the criticisms levelled against western healthcare and education systems is emphasis on individualism, private sector, and minimal role of the state intervention in citizen's welfare. Thus, undermining human agency, social solidarity and care, including respect for the environment. It has perpetuated social inequalities and injustices in society, including access to healthcare, education and other services. The outbreak of COVID-19 as a global pandemic has brought a new perspective on the role of the state in such a health crisis.

Example is given of the Italian philosopher, Giorgio Agamben (2006) who in late February 2020, criticized the Italian media and government for prescribing, quarantining and social distancing without sufficient evidence that COVID-19 was any different from the usual influenza virus. According to him these measures created what he has described in his work as a 'state of exception', i.e. a heavily militarised situation in which the government acquires unusual powers over citizens and 
their civic freedoms. In a state of exception, the state authorities restrict freedoms in the name of 'safety' that they alone can allegedly guarantee. The paper supports the view that the quarantines, lockdowns, and governmental monitoring which recently took place globally in the outbreak of COVID19, reminded people of what French philosopher Paul-Michel Foucault (1926 - 1984), described as an exceptional mode of political control introduced by the plague in 18th-century Europe. In his opinion, the state isolating people to prevent the spread of an infectious diseases is a blatant display of unlimited power (Foucault 1969). The paper backs the view that whereas Giorgio Agamben changed his mind on the severity of COVID-19 due to the death of more than 10000 people in Italy alone, his Foucaultinspired argument about a 'state of exception' emphasizes that in a neoliberal world order, governmental 'power' is inseparable from the interests of the private sector and the market economy. Using the African Ubuntu philosophy of social solidarity and care, the paper has the view that the state of exception could be an opportunity for change, the world over, to mobilise for comprehensive people-centric safety nets and refuse to be content with trickle-down measures and pro-market corporate bailouts.

Some of the IK holders expressed the view that in a matter of weeks a virus (COVID-19) has managed to transform governments. They shut down businesses, closed people indoors and promised trillions of dollars to keep the global economy on life support. According to (WHO 2020), the state which was much criticized, is now in its essential role as the Leviathan, the preventer of anarchy, and the ultimate insurance against an intolerable human condition in which life is 'solitary, poor, nasty, brutish, and short' (Schmitt 1996). For instance, in all countries where the coronavirus first appeared and spread such as China, South Korea, Iran, Singapore, Thailand, Taiwan, Hong Kong and Italy, the state has led the war against it. It imposed draconian lockdowns on entire populations, ruthlessly sacrificing personal liberty to security (World Economic Forum 2020).

In many other countries, the world over, political leaders are increasingly realizing that they will be judged through their administrative capacity to check the spread of this pandemic. The IK holders expressed the view that in 2020, more than ever, the COVID-19, has managed to put public healthcare as the highest priority, at all levels, locally, nationally and globally, as government policies are developed and implemented to protect all sections of society from the pandemic. The paper stresses that COVID- 
19 has become a global public health concern that requires a large public health response in line with African Ubuntu values.

\section{Conclusion}

The study used a telecommunication survey and a purposive sample of IK holders, across cultures, supported by secondary data sources, to investigate IK holders' views on the following issues during COVID-19: their conceptualization of IK and its role in mitigating pandemics such as COVID19; IK holders' perspectives on challenges and prospects of co-knowledge creation and sharing in healthcare research; the African Ubuntu philosophy and role of the state during global pandemics such as COVID-19.

It was found that although the majority of the marginalized Africans depended on their IKS for healthcare including mitigation against global pandemics, IKS tend to be neglected in the search for sustainable solutions against global pandemics due to dominance of western science. The majority of the IK holders lived in the marginalized communities with the people, they knew their concerns and assisted them with holistic prevention and treatment measures, which are locally accessible, affordable and culturally acceptable; the IK holders conceptualized IK as holistic, cultural, placed-based, spiritual, oral, multi-generational and inclusive in nature. They expressed the view that research in Africa, like formal education, has been used as a tool of colonization and exploitation of indigenous communities. On the issue of Ubuntu values and the state during COVID-19, they indicated that in a matter of weeks a virus, has transformed governments, worldwide. They have shut down businesses, closed people indoors and promised trillions of dollars to keep the global economy on life support.

The following recommendations were made: indigenous knowledge should be recognized as an integral part of promoting democracy and complementarity of knowledge systems in the global knowledge economy. The majority of the marginalized communities, depend on IK for livelihood including mitigation against pandemics; the mitigation of global pandemics has cultural imperatives; therefore, mitigation should not be left to western science alone; governments should endeavour to mobilize community-based support systems through partnerships with traditional healers, traditional leaders and other stakeholders, at all levels of society. This will make interventions inclusive and locally acceptable; research and education in 
Africa, requires new epistemologies, conceptual and methodological frameworks as part of decolonization, self-determination and IK contribution to the global pool of knowledge; during times of pandemics, when information is changing rapidly, there is need to engage local communities in their own local languages and cultural values to build trust and public acceptance of interventions.

\section{References}

Abele, F. 1997. Traditional Knowledge in Practice. Arctic 50,4: 3 - 5. https://doi.org/10.14430/arctic1110

Agamben, G. 2006. State of Exception. (Stato di eccezione.) Attell, K (trans.). International Journal of Constitutional Law 4,3: 567 - 575. https://doi.org/10.1093/icon/mol023

Agrawal, A. 2005. Dismantling the Divide between Indigenous and Scientific Knowledge. Development and Change 26,3: 413 - 439.

https://doi.org/10.1111/j.1467-7660.1995.tb00560.x

Barth, F. 2002. An Anthropology of Knowledge. Current Anthropology 43,1: 1 - 18 .

https://doi.org/10.1086/324131

Battiste, M. 2005. Research Ethics for Protecting Indigenous Knowledge and Heritage: Institutional and Researcher Responsibilities. In Denzin, N., Y. Lincoln \& Y. Smith (eds.): Handbook of Critical and Indigenous Methodologies. London: Sage.

https://doi.org/10.4135/9781483385686.n25

Bond, P. 2020. Covid-19 Attacks the Down-and-out in Ultra-unequal South Africa. Solidarity 16 April: 1.

Brascoupé, S. \& H. Mann 2001. A Community Guide to Protecting Indigenous Knowledge Systems. Ottawa: Department of Indian and Northern Development of Canada.

Denzin, N. \& Y. Lincoln 2008. Critical Methodologies and Indigenous Inquiry. In Denzin, N., Y. Lincoln \& L.T. Smith (eds.): Handbook of Critical and Indigenous Methodologies. London: Sage.

https://doi.org/10.4135/9781483385686.n1

Etowa, J., W. Bernard, B. Oyinsn \& B. Clow 2007. Participatory Action Research: An Approach for Improving Black Women's Health in Rural 
and Remote Communities. Journal of Transcultural Nursing 18,4: 349 - 357. https://doi.org/10.1177/1043659607305195

PMid:17911575

Fleming, J. \& R.J. Ledogar 2008. Resilience and Indigenous Spirituality: A

Literature Review. Pimatisiwin Summer, 6, 2: 47 - 64.

Foucault, M. 1969. The Archaeology of Knowledge. New York: Pantheon.

Grasswick, H. 2010. Scientific and Lay Communities: Earning Epistemic

Trust through Knowledge Sharing. Synthese 177: 387 - 409.

https://doi.org/10.1007/s11229-010-9789-0

Getty, G. 2010. The Journey between Western and Indigenous Research

Paradigms. Journal of Transcultural Nursing 21,5: 5 - 14.

https://doi.org/10.1177/1043659609349062

PMid:19820173

Greenwood, D. \& M. Levin 1998. Introduction to Action Research: Social Research for Social Change. Thousand Oaks, CA: Sage.

Hart, M. 2010. Indigenous Worldviews, Knowledge, and Research: The

Development of an Indigenous Research Paradigm. Journal of Indigenous Voices in Social Work 1,1: 1 - 16.

Hatcher, A., C. Bartlett, A. Marshall \& M. Marshall 2009. Two-eyed Seeing in the Classroom Environment: Concepts, Approaches, and Challenges. Canadian Journal of Science, Mathematics and Technology Education 9,3: $141-153$.

https://doi.org/10.1080/14926150903118342

Israel, B., E. Eng, A. Schulz \& E. Parker 2005. Methods in Community-Based Participatory Research for Health. San Francisco: John Wiley.

Iwama, M., M. Marshall, A. Marshall \& C. Bartlett 2009. Two-Eyed Seeing and the Language of Healing in Community-Based Research. Canadian Journal of Native Education 32,2: 3 - 23.

Kirmayer, L., G. Brass \& V. Tait 2000. The Mental Health of Aboriginal Peoples: Transformations of Identity and Community. Canadian Journal of Psychiatry 45: 607 - 616.

https://doi.org/10.1177/070674370004500702

PMid:11056823

Mazrui, A. 1986. The African Triple Heritage. New York: Little Brown \& Co.

Mkhize, B.V.K. 2020. Marginalization of Indigenous Healers City Press 24 April 2020. 
Oelofsen, R. 2015. Decolonisation of the African Mind and Intellectual Landscape. Phronimon 16, 2: 130 - 146.

https://doi.org/10.25159/2413-3086/3822

Olusola, O. 2007. Dynamics of Indigenous Language in Environmental Communication. Lagos Papers in English Studies 1,1: 228 - 235.

Ortiz, O. 1999. Understanding Interactions between Indigenous Knowledge and Scientific Information. Indigenous Knowledge and Development Monitor 7,3: 7 - 10.

Schmitt, C. 1996. The Leviathan in the StateTheory of Thomas Hobbes:

Meaning and Failure of a Political Symbol. Westport, Conn.: Greenwood Press.

Weber-Pillwax, C. 2001. What is Indigenous Research? Canadian Journal of Native Education 25,2: 166 - 174.

Wilson, S. 2008. Research is Ceremony: Indigenous Research Methods. Winnipeg: MB: Fernwood Publishing.

World Health Organization (WHO) 2020. African Countries Move from COVID-19 Readiness to Response as Many Confirm Cases. Geneva: WHO.

World Economic Forum 2020. The Threat of Coronavirus in Africa Flags a Deeper Crisis of Global Solidarity. Geneva: World Economic Forum.

Hassan O. Kaya DSI-NRF Centre in Indigenous Knowledge Systems University of KwaZulu-Natal South Africa kaya@ukzn.ac.za

Mayashree Chinsamy DSI-NRF Centre in Indigenous Knowledge Systems University of KwaZulu-Natal South Africa Chinsamym@ukzn.ac.za 